\title{
Curly Top Survey in the Western United States
}

\author{
C. A. Strausbaugh, W. M. Wintermantel, A. M. Gillen, and I. A. Eujayl
}

First and fourth authors: U.S. Department of Agriculture-Agricultural Research Service (USDA-ARS) NWISRL, 3793 North 3600 East, Kimberly, ID 83341; second author: USDA-ARS, 1636 East Alisal St., Salinas, CA 93905; and third author: USDA-ARS CGPRU, 141 Experiment Station Rd., Stoneville, MS 38776.

Accepted for publication 10 July 2008.

\begin{abstract}
Strausbaugh, C. A., Wintermantel, W. M., Gillen, A. M., and Eujayl, I. A. 2008. Curly top survey in the western United States. Phytopathology 98:1212-1217.

Curly top in sugar beet continues to be a challenging disease to control in the western United States. To aid in development of host resistance and management options, the curtovirus species composition was investigated by sampling 246 commercial fields along with nursery and field trials in the western United States. DNA was isolated from leaf samples and the

western United States, while only a few isolates of Beet curly top virus (BCTV) were found. In phylogenetic analysis, BSCTV, BMCTV, and BCTV isolates formed distinct groups in the dendrogram. Seven isolates not amplifiable with species-specific primers did amplify with curly top coat protein primers, indicating novel curtovirus species or strains may be present. Given the wide host range of the viruses responsible for curly top, frequent co-infections, and genetic diversity within and among species, establishing better host resistance, and controlling curly top will continue to be a challenge.
\end{abstract} species were identified using species-specific polymerase chain reaction primers for the $C l$ gene. Amplicons from 79 isolates were also sequenced to confirm identifications. Beet severe curly top virus (BSCTV) and Beet mild curly top virus (BMCTV) were widely distributed throughout the
Additional keywords: beet leafhopper, Beta vulgaris, Circulifer tenellus, geminivirus.
Curly top in sugar beet (Beta vulgaris L.) is a considerable problem in semiarid areas of the western United States and other semiarid parts of the world such as the Middle East and countries bordering the Mediterranean Sea $(4,5,7,10,12)$. Curly top can be caused by a number of closely related species in the genus Curtovirus of the family Geminiviridae. These viruses are transmitted by the beet leafhopper (Circulifer tenellus Baker) and can infect dicotyledonous hosts from 44 families and at least 300 species $(4,10)$. The viruses responsible for curly top diseases have been separated into three distinct species, based largely on sequence variation in select regions of the curtovirus genome, as well as some differences in host range and disease severity (22). With these species and more recently discovered species, the genus Curtovirus now comprises Beet curly top virus (BCTV; formerly the $\mathrm{Cal} /$ Logan strain), Beet mild curly top virus (BMCTV; formerly the Worland strain), Beet severe curly top virus (BSCTV; formerly the CFH strain), Horseradish curly top virus (HrCTV), and Spinach curly top virus (SCTV) $(2,3,7$, $13,15,18,26)$. Recombination has also been suggested to have played a part in the evolution of species in this group $(2,6,9$, $15,20)$. BCTV may have arisen by recombination between a whitefly-transmitted geminivirus, which may have donated the complementary genes involved in virus replication, and a leafopper-transmitted geminivirus, which donated the coat protein gene (20). However, the ancestors have not been identified as they have been for HrCTV (15).

Curtovirus species possess a monopartite genome with circular single-stranded DNA of approximately $3 \mathrm{~kb}$ with three over-

Corresponding author: C. A. Strausbaugh

E-mail address: Carl.Strausbaugh@ars.usda.gov

doi:10.1094/PHYTO-98-11-1212

This article is in the public domain and not copyrightable. It may be freely reprinted with customary crediting of the source. The American Phytopathological Society, 2008. lapping virion sense genes $(V 1, V 2$, and $V 3)$, four overlapping complementary sense genes $(C 1, C 2, C 3$, and $C 4)$, and an intergenic region containing the origin of replication $(2,8,13,17$, $19,22,24)$. Virion sense genes are conserved among characterized strains with $>95 \%$ amino acid percent sequence identity, while the complementary sense genes are more divergent (21). The four complementary sense genes had $71,62,82$, and $53 \%$ amino acid percent sequence identity for $C 1, C 2, C 3$, and $C 4$, respectively (21). $C 1$ and $C 3$ genes are important in replication while the $C 2$ gene is involved in pathogenicity $(16,19,22,24)$.

Curly top nearly eliminated the sugar beet industry in the western United States until cultivars with resistance became widely available in the mid 1930s (4). However, the use of host resistance combined with foliar and systemic insecticides only reduces disease incidence $(14,27,28)$, and even the most resistant sugar beet varieties can be significantly impacted if infected as young plants $(11,29)$. Curly top disease pressure still leads to considerable economic losses in areas of the western United States on an annual basis, as emphasized by the Environmental Protection Agency issuing an emergency Section 18 exemption for clothianidin to control the beet leafhopper in 2006, 2007, and 2008 (28). During the period from the 1950s to the 1970s a broad range of curly top isolates were described, and some were noted to have increased in severity (11). A survey of curtovirus species conducted in the western United States from 1994 to 1995 , examined 58 isolates from the field and established that BSCTV or BMCTV were present in sugar beet and BCTV (Cal/Logan) was not found (25). When eight isolates from the laboratory and Idaho nurseries were studied, BCTV was also found (25). Since that time new curtovirus species have been identified in the western United States on other crops $(2,15)$ and curly top losses in sugar beet have increased in areas of the western United States Thus, the curly top species composition in the western United States was reinvestigated to determine the curtovirus species associated with curly top in sugar beet. 


\section{MATERIALS AND METHODS}

Collection of sugar beet leaf samples. Samples were collected from the sugar beet production areas in the western United States where curly top has been observed, with the exception of the state of Washington. Sugar beet leaf (still expanding) samples symptomatic for curly top were collected from three individual plants and pooled to establish a composite sample from 101 and 145 separate fields in 2006 and 2007, respectively. In addition, samples from six individual plants were collected each year from the Curly Top Nursery maintained by the Beet Sugar Development Foundation and the USDA-ARS in Kimberly, ID in 2006 and 2007. In 2006, samples from 12 individual plants were collected from a field in the Grandview, ID area to examine potential variation within fields. In 2007, three individual plant samples were collected from seed treatment insecticide trials near Kimberly and Nampa, ID. Individual plant samples from common bean (Phaseolus vulgaris), pumpkin (Cucurbita maxima), and squash (Cucurbita pepo), near Prosser and Toppenish, WA were collected from Washington and kindly provided by R. Larsen (USDA-ARS, Prosser, WA). Leaf samples from plants inoculated with well characterized isolates maintained at the USDA-ARS laboratory in Salinas, CA served as controls for BSCTV (plants originally inoculated with a CFH clone provided by D. Stenger) and BMCTV (plants originally inoculated with Worland 4 provided by R. L. Gilbertson). Purified plasmids containing the genome of BCTV were provided by D. Stenger for the BCTV control DNA.

DNA extraction and polymerase chain reaction (PCR). Leaf tissue was sampled by punching out a disk with the cap of a sterile 2-ml microcentrifuge tube from each of four leaves per sample and stored at $-80^{\circ} \mathrm{C}$. Individual tubes containing the frozen tissue were dipped in liquid nitrogen and then pulverized using a Retsch MM 301 mixer mill (Retsch, Inc., Newton, PA) with 5-mm stainless steel beads. DNA was extracted using a DNeasy Plant Mini Isolation kit (Qiagen, Inc., Valencia, CA) following standard protocols suggested by the manufacturer, except DNase and RNase free water (W4502, Sigma-Aldrich, St. Louis, MO) was used in place of Buffer AE in the final steps. The DNA was stored at $-20^{\circ} \mathrm{C}$.

PCR were performed in volumes of $25 \mu \mathrm{l}$ with the components in the master mix at the following concentrations: $1 \times$ PCR buffer (GeneAmp 10× PCR Gold buffer with $150 \mathrm{mM}$ Tris-HCl, $\mathrm{pH}$ 8.0, $500 \mathrm{mM} \mathrm{KCl}$; Applied Biosystems, Foster City, CA), $2.5 \mathrm{mM}$ $\mathrm{MgCl}_{2}$ (Applied Biosystems), $200 \mu \mathrm{M}$ dNTPs (Applied Biosystems), $0.2 \mu \mathrm{M}$ primers, 0.65 units AmpliTaq Gold (Applied Biosystems), and $60 \mathrm{ng}$ DNA. Amplification consisted of $5 \mathrm{~min}$ at $95^{\circ} \mathrm{C}$ followed by 34 cycles $95^{\circ} \mathrm{C}$ for $1 \mathrm{~min}, 54^{\circ} \mathrm{C}$ for $1 \mathrm{~min}$, and $72^{\circ} \mathrm{C}$ for $1 \mathrm{~min}$. After the last cycle, the reaction was held at $72^{\circ} \mathrm{C}$ for $5 \mathrm{~min}$ and then $4^{\circ} \mathrm{C}$.

Samples were tested for the presence of curtovirus species by PCR amplification of the replication-associated protein (rep) gene using the following species-specific primers: BSCTV-C1 $2315 \mathrm{~F}$ 5'-CGGAATCCAAACCAAAATAAGAATC-3' and BSCTV-C1 2740R 5'-AAGTCCAGATTCGTAATGCCCGT-3', region amplified matches a 426-bp segment from GenBank accession U02311 (BSCTV-CFH complete genome); BMCTV-C1 2213F 5'-GGCATCCACCCCGAAATAAGAATC-3' and BMCTV-C1 2609R 5'-CGACATCACTCATCCTTCCTCAAGC-3', region amplified matches a 397-bp segment from GenBank accession AY134867 (BMCTV-Worland4 complete genome); and BCTV-C1 2097F 5'TGCTCCAATAAGGTGCTTCCAGTG-3' and BCTV-C1 2387R 5'-TTTCCTCTGTCCTCATTCACAAACG-3', region amplified matches a 291-bp segment from GenBank accession AF379637 (BCTV-Cal/Logan complete genome). For isolates that did not produce an amplicon using these species-specific primers, we developed an internal standard to prove inhibitors of PCR were not present and the DNA was amplifiable based on PCR ampli- fication of a highly conserved internal transcribed spacer (ITS) region of 5.8S rDNA. Primers (ITS-Con293F 5'-AGCGAAATGCGATACTTGGT-3' and ITS-Con603R 5'-GGCAACATGTTAGGGTCCTG-3') amplify a 311-bp fragment from GenBank accession AY858597 (Beta vulgaris L. 5.8S ribosomal gene). ITS positive samples were then amplified using coat protein primers designed to amplify a 496-bp fragment from all known curtovirus-related species: BCTV2-F 5'-GTGGATCAATTTCCAGACAATTATC-3' and BCTV2-R 5'-CCCATAAGAGCCATATCAAACTTC-3' corresponding to nucleotides 446 to 964 of GenBank accession U02311. Amplification products were electrophoresed through agarose gels $(2 \% \mathrm{wt} / \mathrm{vol})$ supplemented with ethidium bromide $(0.002 \mathrm{mg} / \mathrm{ml})$ in TBE buffer $(89 \mathrm{mM}$ Tris base, $89 \mathrm{mM}$ boric acid, and $2 \mathrm{mM}$ EDTA). DNA from the control sources mentioned in the previous section were amplified, sequenced, and represent the controls $(\mathrm{BSCTV}=\mathrm{BSCTVCON}, \mathrm{BMCTV}=$ BMCTVCON, and BCTV $=$ BCTVCON) in the dendrogram in Figure 1.

Amplicons produced from 79 isolates (67 field isolates, seven nursery [BMCTV06-102ID, BMCTV06-103ID, BMCTV06105ID, BMCTV06-106ID, BMCTV07-10ID, BMCTV07-17ID, and BSCTV07-17ID] isolates, and two seed treatment trial [BMCTV07-14ID and BMCTV07-19ID] isolates and three control samples) using species-specific primer combinations and from seven isolates using the coat protein primer set were sent to MC Lab (Molecular Cloning Laboratory, San Francisco, CA) for sequencing. Results were compared to known accessions of each curtovirus species available in GenBank to confirm species identity using BLASTn 2.2.17 (1). DNA sequences were aligned using ClustalX version 2.0. Phylogenetic analysis was performed using PAUP 4.0 Beta version 10 (PAUP; D. L. Swofford, Laboratory of Molecular Systematics, Smithsonian Institution). Maximum parsimony analysis was performed with the heuristic search with simple taxon addition sequences, tree bisection-reconnection (TBR) branch swapping, and MaxTrees $=100$. Distance matrix analysis was conducted with the neighbor-joining (NJ) algorithm and the Jukes-Cantor genetic distance model (calculates divergence time; $0=$ isolate sequences were the same). Confidence intervals in tree topologies were estimated by bootstrap analysis with 1,000 replicates. Only nodes with bootstrap values over $50 \%$ were considered significant. The resulting trees were visualized using the program TreeView $\mathrm{X}$ version 0.5.0 (Rodrick D. M. Page, University of Glasgow, Scotland).

\section{RESULTS}

PCR amplification. All samples from the Curly Top Nursery in Kimberly, ID were positive for the three curtoviruses (BSCTV, BMCTV, and BCTV) both years (Table 1). The 2006 Grandview, ID samples were 83,100 , and $33 \%$ positive for BSCTV, BMCTV, and BCTV, respectively. The three samples from the 2007 insecticide seed treatment trial in Kimberly, ID (same field as Curly Top Nursery) each contained all three species, while the three samples from the trial near Nampa, ID only contained BMCTV. California samples were only tested in 2007, and were 94, 6, and $0 \%$ positive for BSCTV, BMCTV, and BCTV, respectively. Colorado samples were 14, 100, and 5\% positive in 2006 and 33, 87, and $0 \%$ positive in 2007 for BSCTV, BMCTV, and BCTV, respectively. Two of the 2007 Colorado samples were positive using ITS primers, but were negative using coat protein and species specific primers, indicating they had amplifiable DNA but no detectable curtovirus species. Idaho survey samples were 60 , 80, and $10 \%$ positive in 2006 and 63, 13, and $0 \%$ positive in 2007 for BSCTV, BMCTV, and BCTV, respectively. Seven Idaho samples were positive using ITS primers and negative using coat protein and species specific primers in 2007, indicating that they had amplifiable DNA but no detectable curly top virus. Both years, two Idaho samples were negative for all three species but 
positive using both ITS and coat protein primers, suggesting that either significantly diverged curtovirus isolates, or perhaps novel curtovirus strains or species may be present. Montana samples were 100, 100, and $0 \%$ positive in 2006 and 100, 86, and 0\% positive in 2007 for BSCTV, BMCTV, and BCTV, respectively. The Nebraska samples contained 100, 100, and 0\% in 2006 and 25, 75, and 0\% in 2007 for BSCTV, BMCTV, and BCTV, respectively. One sample was positive using ITS primers, but negative using coat protein primers, indicating the DNA was amplifiable but no detectable curtovirus species were present. Oregon samples had 100, 80, and $20 \%$ in 2006 and 100, 33, and $0 \%$ in 2007 for BSCTV, BMCTV, and BCTV, respectively. Wyoming samples were 100,100, and $0 \%$ positive in 2006 and 88, 46, and $0 \%$ positive in 2007 for BSCTV, BMCTV, and BCTV, respectively. In 2007, three of the Wyoming samples were positive using both ITS and coat protein primers, again suggesting that either significantly diverged curtovirus isolates, or perhaps novel curto- virus strains or species may be present. Fourteen samples from the state of Washington from bean, pumpkin, and squash contained only BMCTV isolates and no BSCTV or BCTV (data not shown).

BSCTV and BMCTV were found in the same composite sample from individual fields $50 \%$ of the time in samples from Idaho, Montana, and Wyoming. Samples positive for BCTV also contained both BSCTV and BMCTV.

Sequencing. BLASTn results indicated the virus species identified for all 79 sequenced isolates (included three controls) confirmed the species identified through amplicon size in gel analysis. The amplicons for 26 of the isolates were considered abnormal (usually larger than expected) when compared to the controls and the expected length based on primer position. This abnormality did not influence identification with BLASTn, since all isolates with a match on BLASTn had the same species identification as determined based on amplicon size analysis.

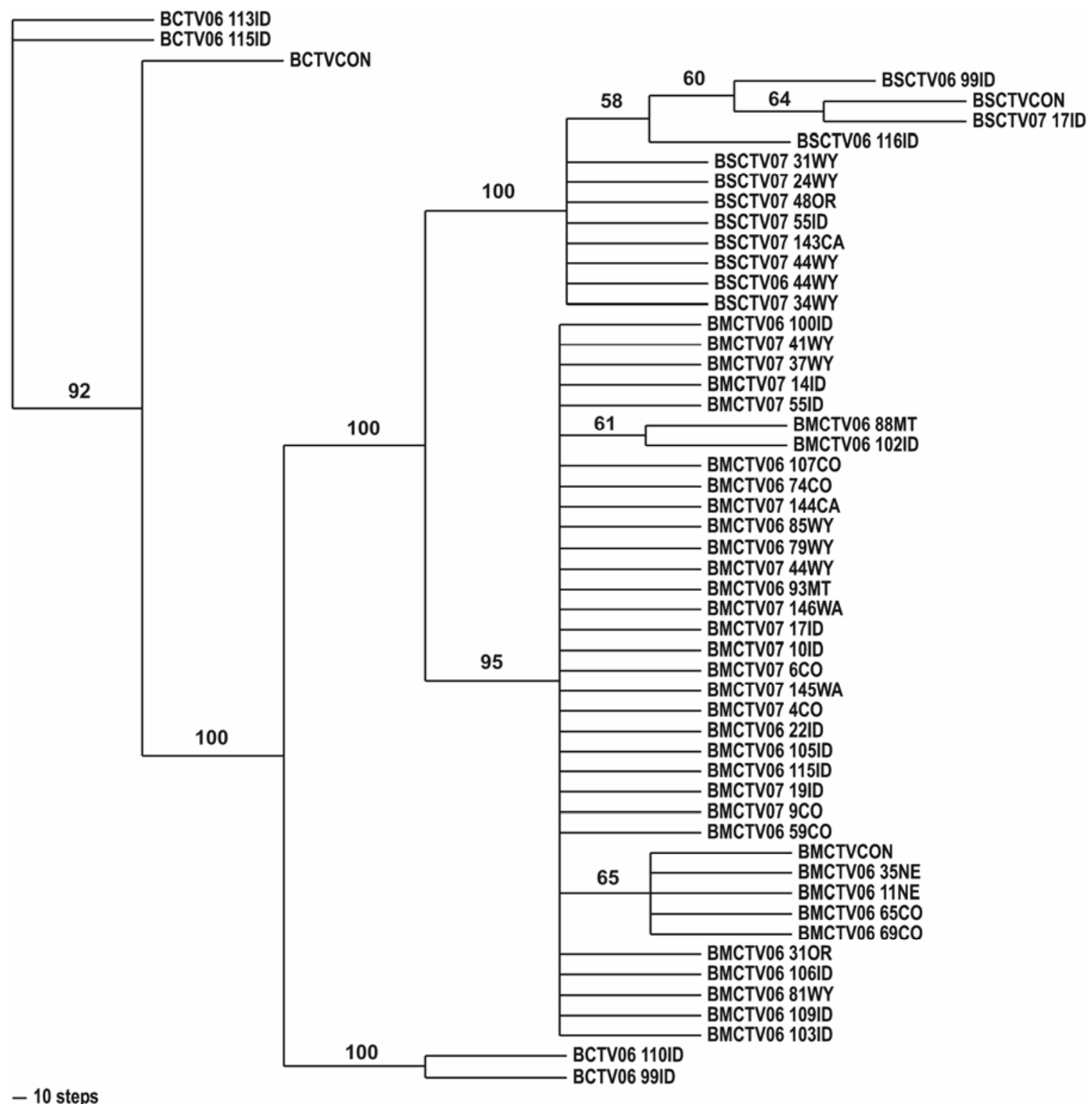

Fig. 1. Phylogenetic comparison of sequences with phylogenetic analysis using parsimony of the $C 1$ gene from 48 curtovirus isolates from sugar beet, one curtovirus isolate from pumpkin (BMCTV07-145WA), one curtovirus isolate from squash (BMCTV07-146WA), and three controls (CON) in a bootstrap 50\% majority-rule consensus tree. The tree length is 767 steps with 276 parsimony-informative characters along with consistency index $(\mathrm{CI})=0.7236$ and retention index $(\mathrm{RI})=0.8585$. The relative support for each clade is indicated by bootstrap values on branches. Isolate designations were coded as follows: species (BSCTV = Beet severe curly top virus, BMCTV = Beet mild curly top virus, and BCTV = Beet curly top virus), year of collection, isolate number, and state collected. The BMCTVCON DNA originated from a plant infected by a Worland 4 isolate. Accession numbers for sequences deposited in GenBank range from EU857484 to EU857536. 
Isolates with abnormal sequence lengths were not included in the phylogenetic analysis. Amplicons produced with the BSCTV, BMCTV, and BCTV primers that were included in the phylogenetic analysis had an average size of 381, 380, and $275 \mathrm{bp}$, respectively. Sequence alignments in ClustalX (data not shown) confirmed identifications and groupings established in the BLASTn and amplicon size analysis results.

BSCTV sequences. Amplicons produced from 28 isolates (includes BSCTV control) using the BSCTV primers were sequenced and found to have 99 to $96 \%$ identity with accession U02311 (BSCTV-CFH complete genome) in GenBank. Phylogenetic analysis placed the BSCTV isolates together in one group in the dendrogram (Fig. 1). Isolates BSCTV07-17ID and BSCTVCON showed some divergence from the rest of the BSCTV isolates. However, the largest genetic distance between any of the BSCTV isolate comparisons was 0.052. Accession numbers for BSCTV sequences deposited in GenBank are BSCTVCON, EU857484; BSCTV07_143CA, EU857485; BSCTV06_116ID，EU857486; BSCTV06_44WY，EU857487; BSCTV06_99ID, EU857488; BSCTV07_17ID, EU857489; BSCTV07_24WY, EU857490; BSCTV07_31WY, EU857491; BSCTV07_34WY, EU857492; BSCTV07_44WY, EU857493; BSCTV07_48OR, EU857494; and BSCTV07_55ID, EU857495.

BMCTV sequences. Amplicons produced by 20 isolates (including the BMCTV control) using the BMCTV primers were sequenced and found to have 100 to $96 \%$ identity with accession U56975 (BMCTV-Worland complete genome). Amplicons produced by 10 other isolates using the BMCTV primers were sequenced and found to have 100 to $96 \%$ identity with accession AY134867 (BMCTV-Worland4 complete genome). Thus, 73\% of the isolates that produced fragments with the BMCTV primers had 100 to $96 \%$ identity with one of the two fully sequenced BMCTV accessions. The remaining putative BMCTV amplicons had lower levels of identity with the two BMCTV accessions: 95 to $90 \%$ for 3 isolates (BMCTV06-65CO, BMCTV06-105ID, and BMCTV06-109ID), 89 to $80 \%$ for 6 isolates (BMCTV06-31OR, BMCTV06-81WY, BMCTV06-96MT, BMCTV06-103ID, BMCTV06-106ID, and BMCTV07-6CO), and 79 to $70 \%$ for 2 isolates (BMCTV06-10WY and BMCTV06-19ID). Phylogenetic analysis placed the BMCTV isolates out into one large group in the dendrogram with two minor subgroups (Fig. 1). When comparing BMCTV isolates, BMCTV07-6CO was the most divergent from the other isolates in the BMCTV cluster with a distance value of 0.282 . Generally, divergence among isolates in this group was low with a range of distance values from 0.282 to 0.081 . For example, isolate BMCTV07-6CO was most similar to BMCTV07$4 \mathrm{CO}$ with a distance value of 0.174 . When comparing BMCTV06-103ID versus BMCTV06-100ID, the distance matrix had a value of 0.081. When comparing BMCTV06-103ID with the BCTV isolates, BCTV06-110ID and BCTVCON, the distances were 1.487 and 1.368 , respectively. This large separation between BMCTV and BCTV isolates was also evident in the dendrogram. When comparing BMCTV07-6CO with the BCTV isolates, BCTV06-110ID and BCTVCON, the distances were 2.329 and 1.479, respectively. When comparing BMCTV07-6CO with the BSCTV isolates, BSCTV06-99ID and BSCTV07-34WY, the distances were 0.458 and 0.449 , respectively. This large separation between BMCTV and BSCTV isolates was also evident in the dendrogram. Both the dendrogram and distance data suggest that the BMCTV isolates were more closely related to the BSCTV isolates than the BCTV isolates. BMCTV isolates from Idaho were representative of the full range of diversity in this species based on $C 1$ data. Accession numbers for BMCTV sequences deposited in GenBank are BMCTVCON, EU857501; BMCTV07_144CA, EU857502; BMCTV07_146WA, EU857503; BMCTV07_145WA, EU857504; BMCTV06_100ID, EU857505; BMCTV06_102ID, EU857506; BMCTV06_103ID, EU857507; BMCTV06_105ID, EU857508; BMCTV06_106ID, EU857509; BMCTV06_107CO, EU857510; BMCTV06_109ID, EU857511, BMCTV06_115ID, EU857512; BMCTV06_11NE, EU857513; BMCTV06_22ID, EU857514; BMCTV06_31OR, EU857515; BMCTV06_35NE, EU857516; BMCTV06_59CO, EU857517; BMCTV06_65CO, EU857518; BMCTV06_69CO, EU857519; BMCTV06_74CO, EU857520; BMCTV06_79WY, EU857521; BMCTV06_81WY, EU857522; BMCTV06_85WY, EU857523; BMCTV06_88MT, EU857524; BMCTV06_93MT, EU857525; BMCTV07_10ID, EU857526; BMCTV07_14ID, EU857527; BMCTV07_17ID, EU857528; BMCTV07_19ID, EU857529; BMCTV07_37WY, EU857530; BMCTV07_41WY, EU857531; BMCTV07_44WY, EU857532; BMCTV07_4CO, EU857533; BMCTV07_55ID, EU857534; BMCTV07_6CO, EU857535; and BMCTV07_9CO, EU857536.

BCTV sequences. Amplicons produced by 10 isolates (includes control) using the BCTV primers were sequenced and

TABLE 1. The curtovirus species associated with curly top in sugar beets in the western United States was established through a survey of symptomatic plants during the 2006 and 2007 growing seasons

\begin{tabular}{|c|c|c|c|c|c|c|c|c|c|c|c|c|}
\hline \multirow[b]{3}{*}{ Collection location } & & & \multicolumn{6}{|c|}{ Samples positive for this species ${ }^{\mathrm{a}}$} & \multicolumn{4}{|c|}{ Not positive for any species ${ }^{b}$} \\
\hline & \multicolumn{2}{|c|}{ No. of samples } & \multicolumn{2}{|c|}{ BSCTV } & \multicolumn{2}{|c|}{ BMCTV } & \multicolumn{2}{|c|}{ BCTV } & \multicolumn{2}{|c|}{2006} & \multicolumn{2}{|c|}{2007} \\
\hline & 2006 & 2007 & 2006 & 2007 & 2006 & 2007 & 2006 & 2007 & ITS & $\mathrm{CP}$ & ITS & $\mathrm{CP}$ \\
\hline California & NT & 17 & NT & 16 & NT & 1 & NT & 0 & NT & NT & 0 & 0 \\
\hline Colorado & 22 & 21 & 3 & 5 & 22 & 19 & 1 & 0 & 0 & 0 & 2 & 0 \\
\hline Idaho & 30 & 30 & 18 & 19 & 24 & 4 & 3 & 0 & 2 & 2 & 9 & 2 \\
\hline Montana & 10 & 22 & 10 & 22 & 10 & 19 & 0 & 0 & 0 & 0 & 0 & 0 \\
\hline Wyoming & 32 & 48 & 32 & 42 & 32 & 22 & 0 & 0 & 0 & 0 & 4 & 3 \\
\hline Total & 101 & 145 & 70 & 108 & 94 & 69 & 5 & 0 & 2 & 2 & 16 & 5 \\
\hline \multicolumn{13}{|l|}{ Other samples ${ }^{\mathrm{c}}$} \\
\hline Seed Trt - Nampa & NT & 3 & NT & 0 & NT & 3 & NT & 0 & NT & 0 & NT & 0 \\
\hline Seed Trt - Kimberly & NT & 3 & NT & 3 & NT & 3 & NT & 3 & NT & 0 & NT & 0 \\
\hline Curly Top Nursery & 6 & 6 & 6 & 6 & 6 & 6 & 6 & 6 & 0 & 0 & 0 & 0 \\
\hline Grandview, ID & 12 & NT & 10 & NT & 12 & NT & 4 & NT & 0 & 0 & NT & NT \\
\hline
\end{tabular}

${ }^{\text {a }}$ Curly top virus strains are now recognized as species as follows: BSCTV = Beet severe curly top virus (formerly CFH strains), BMCTV = Beet mild curly top virus (formerly Worland strains), and BCTV = Beet curly top virus (formerly Cal/Logan strains). NT = not tested.

b Samples in these columns were negative for all three species-specific primers. An internal transcribed spacer (ITS) positive reaction indicates DNA was present and there were no inhibitors in the reaction. A positive for a general coat protein (CP) primer indicates the strain was likely to be curly top but potentially different from known species.

${ }^{\mathrm{c}}$ Seed Trt - Nampa = insecticide seed treatment trial conduced south of Nampa, ID; Seed Trt - Kimberly = insecticide seed treatment trial conducted south of Kimberly, ID; Curly Top Nursery = samples from plants in the BSDF Curly Top Nursery in Kimberly, ID; Samples from a commercial field near Grandview, ID 
seven were found to have 100 to $98 \%$ identity with accessions AF379637 (BCTV-Cal/Logan complete genome). The other three isolates had 97 to $96 \%$ identity with accession M24597 (BCTV$\mathrm{Cal} / \mathrm{Log}$ complete genome). The BCTV isolates with expected sequence lengths formed separate groups in the dendrogram. Output from a DNA distance matrix also supports separation of the two groups. Within the BCTVCON, BCTV06-115ID, and BCTV06-113ID group the distances ranged from 0.012 to 0.048 . Within the other group, the distance between the BCTV06-99ID and BCTV06-11ID isolates was 0.250. In isolate comparisons between the two groups, the distances ranged from 1.667 to 2.133. Accession numbers for BCTV sequences deposited in GenBank are BCTVCON, EU857496; BCTV06_110ID, EU857497; BCTV06_113ID, EU857498; BCTV06_115ID, EU857499; and BCTV06_99ID, EU857500.

Coat protein sequences. Of the seven isolates that only produced an amplicon with the ITS and coat protein primers, three produced usable sequence. Isolate 06-22ID had 91 to $90 \%$ identity with the following curly top related accessions: U02311 (BSCTV-CFH complete genome), U56975 (BMCTV-Worland complete genome), X97203 (BSCTV - CFH coat protein gene and ORF), AF379637 (BCTV-Cal/Logan complete genome), M24597 (BCTV-Cal/Logan complete genome), and AY134867 (BMCTV-Worland4 complete genome). Isolate 06-29ID had 90 to 89\% identity with the following curly top related accessions: U02311, AF379637, M24597, U56975, X97203, and AY134867. Isolate $07-22 \mathrm{WY}$ had 96 to $92 \%$ identity with the following curly top-related accessions: X97203, U02311, U56975, AF379637, M24597, and AY134867. In ClustalX, sequences from the three isolates aligned well with one another (data not shown).

\section{DISCUSSION}

Survey results show that BSCTV and BMCTV isolates are wide spread across the western United States confirming results from a 94/95 survey of sugar beet (25) and a 01/02 survey of chile pepper (9). However, some states with no species diversity in the 94/95 study now have diverse populations. For example, Colorado now has BSCTV and Idaho has all three beet curly top species in field populations. Isolates of BCTV were also found in low numbers in Colorado and Oregon along with the Curly Top Nursery in Kimberly, ID. BCTV had not been identified in sugar beet fields in recent years. BCTV was only found in husbanded populations in the 94/95 survey $(25,26)$. A relatively small number of isolates associated with curly top symptoms did not show identity with currently recognized curtovirus species, based on sequence comparisons. Coat protein sequence data for three isolates indicated they were likely curtovirus species, however viral DNA was not amplified using primers specific to any of the three predominant species. They will need to be investigated further to determine if they represent new, previously uncharacterized curtovirus species.

Phylogenetic analysis indicated the isolates from all three curly top species form distinct groups which agree with the results from the PCR marker analysis. Both the dendrogram and the distance data suggested that the BMCTV isolates were more closely related to the BSCTV isolates than the BCTV isolates. Identification of BCTV isolates outside of southern Idaho was unexpected. Previous studies suggested that BCTV was no longer found in the field in most sugar beet production regions (25), and a recent analysis of 46 California sugar beet isolates did not identify BCTV (W. M. Wintermantel, unpublished data). For many years curtovirus species (BSCTV, BMCTV, and BCTV) have been propagated and released to the field each spring in the Curly Top Nursery near Kimberly, ID by the sugar beet industry in an effort to provide consistent infection.

Interestingly, the four isolates of BCTV identified in this survey from Idaho were quite diverse. Isolates BCTV06-99ID and
BCTV06-110ID were quite closely related to each other based on the amplified sequence. These isolates were actually positioned more closely to BMCTV isolates than the other BCTV isolates in the dendrogram, supporting the theory of strains existing as a continuum. These isolates, as well as the other two BCTV isolates and the BCTV control strain (accession M24597) sequenced were all genetically distinct from one another. This broad variability among BCTV isolates suggests speciation of BCTV may be occurring due to time and/or geographic isolation from areas of uniform BCTV infection. The rare occurrence of BCTV in the field suggests that it may be less competitive in sugar beet and other hosts than BMCTV and BSCTV, which are quite common throughout the American sugar beet industry.

In sugar beet, BMCTV is considered less aggressive than BSCTV and BCTV $(22,25)$, but this virus is very common among field curtovirus isolates. BSCTV is also common among field isolates but BCTV has been quite rare in the field since at least the mid 1990s as discussed above. Virulence of isolates in sugar beet may not be a deciding factor in dominance of a species in this virus-sugar beet system, since virulence of these species may vary among other hosts. Both BCTV and BSCTV were shown to be more severe on sugar beet than $\operatorname{BMCTV}(23,26)$. In individual plant samples from the curly top nurseries, seed treatment trials, and Grandview, co-infection was common with BSCTV and BMCTV. Older literature suggests that mixed infections with phenotypically distinct strains of curly top virus were common and the cross protection phenomena seen with strains of plant RNA viruses do not occur with curly top species $(4,26)$. Curly top species may coexist in the same plant and mixed infections with as many as three species may occur (26). Recombination has been documented among curtoviruses $(2,20)$ and with the frequency of mixed infections, the emergence of recombinant viruses resulting from genetic recombination between co-infecting viruses would seem likely.

Fully sequenced BMCTV isolates share genomic nucleotide sequence identity of 79 to $80 \%$ relative to the sequenced isolates of BCTV and BSCTV, respectively (25). SCTV shares a nucleotide sequence identity of 64 to $84 \%$ with the other curtovirus species (2). Curtovirus species were established based on the demarcation threshold of $89 \%$ in the 8th report of the International Committee on the Taxonomy of Viruses (18).

Curly top species in the western United States appear to have experienced selection pressure over the past half century, with the decline of isolates belonging to BCTV (formerly recognized as the California and Logan strains) and an increase in prevalence of isolates of BMCTV and BSCTV. Diversity seems to be on the increase compared to a 94/95 survey (25), although this survey examined considerably more isolates than were examined in the previous study. BCTV isolates may be at a selective disadvantage and are declining in prevalence. Those BCTV isolates still found appear to be much more diverse than are isolates of either BSCTV or BMCTV, suggesting BCTV isolates have been here much longer, probably dating to the origins of the sugar beet industry in the United States in the early 1900s when curly top was first identified $(4,5)$. The presence of possible new strains or species in the population is not unlikely based on incidence of curtovirus isolates not associated with any of the known species, although these are clearly not dominant isolates based on low frequency of such identifications.

Based on the information accumulated in this study it seems unlikely that increased severity of curly top in the Great Plains and Rocky Mountain sugar beet production regions can be explained by the emergence of new curtovirus species. The predominant species remain the same as in the mid-1990s. However, BSCTV appears more prevalent in Colorado than at that time. An increase in BSCTV prevalence as single or mixed infections could possibly have contributed to the increased severity, but this virus has been present for many years in other parts of the region and is 
relatively uniform, genetically. Another possibility is that fluctuations in beet leafhopper vector population and range (C. tenellus may be migrating and increasingly more active in areas traditionally not associated with significant curly top) or interactions resulting from mixed infection involving curly top with other diseases may have more to do with the increase in disease severity in certain areas than changes in virus population structure. Additional investigations will be needed to adequately address the relationship between curly top incidence and other variables affecting sugar beet production in the western United States.

\section{ACKNOWLEDGMENTS}

These data support the objectives of the United States Department of Agriculture CRIS projects 5368-21220-002-00D and 5305-22000-01100D. Partial support was provided by the Western Sugar CooperativeJoint Growers Research Committee. We thank A. Anchieta, J. Doble, M. Funke, L. Hladky, and J. Smith for technical help; and the field representatives and management of Amalgamated Sugar Co., Spreckels Sugar Co., Western Sugar Coop., and Wyoming Sugar Co. for collecting field samples and sending them to us.

\section{LITERATURE CITED}

1. Altschul, S. F., Madden, T. L., Schäffer, A. A., Zhang, J., Zhang, Z., Miller, W., and Lipman, D. J. 1997. Gapped BLAST and PSI-BLAST: A new generation of protein database search programs. Nucleic Acid Res. 25:3389-3402.

2. Baliji, S., Black, M. C., French, R., Stenger, D. C., and Sunter, G. 2004. Spinach curly top virus: A newly described Curtovirus species from southwest Texas with incongruent gene phylogenies. Phytopathology 94:772-779.

3. Baliji, S., Sunter, J., and Sunter, G. 2007. Transcriptional analysis of complementary sense genes in Spinach curly top virus and functional role of C2 in pathogenesis. Mol. Plant-Microbe Interact. 20:194-206.

4. Bennett, C. W. 1971. The curly top disease of sugarbeet and other plants, Monograph No. 7. The American Phytopathological Society, St. Paul, $\mathrm{MN}$.

5. Blickenstaff, C. C., and Traveller, D. 1979. Factors affecting curly top damage to sugarbeets and beans in southern Idaho, 1919-77. Science and Education Administration, Agricultural Reviews and Manuals, Western Series, No. 8. USDA-ARS, Oakland, CA.

6. Briddon, R. W., Bedford, I. D., Tsai, J. H., and Markham, P. G. 1996. Analysis of the nucleotide sequence of the treehopper-transmitted geminivirus, tomato pseudo-curly top virus, suggests a recombinant origin. Virology 219:387-394.

7. Briddon, R., Stenger, D. C., Bedford, I. D., Stanley, J., Izadpanah, K., and Markham, P. G. 1998. Comparison of a beet curly top virus isolate originating from the old world with those from the new world. Eur. J. Plant Pathol. 104:77-84.

8. Choi, I.-R., and Stenger, D. C. 1996. The strain-specific cis-acting element of beet curly top geminivirus DNA replication maps to the directly repeated motif of the ori. Virology 226:122-126.

9. Creamer, R., Hubble, H., and Lewis, A. 2005. Curtovirus infection in chile pepper in New Mexico. Plant Dis. 89:480-486.

10. Creamer, R., Luque-Williams, M., and Howo, M. 1996. Epidemiology and incidence of beet curly top geminivirus in naturally infected weed hosts. Plant Dis. 80:533-535.
11. Duffus, J. E., and Skoyen, I. O. 1977. Relationship of age of plants and resistance to a severe isolate of the beet curly top virus. Phytopathology 67:151-154.

12. Heydarnejad, J., Hosseini Abhari, E., Bolok Yazdi, H. R., and Massumi, H. 2007. Curly top of cultivated plants and weeds and report of a unique Curtovirus from Iran. J. Phytopathol. 155:321-325.

13. Hormuzdi, S. G., and Bisaro, D. M. 1993. Genetic analysis of beet curly top virus: Evidence for three virion sense genes involved in movement and regulation of single- and double-stranded DNA levels. Virology 193:900-909.

14. Kaffka, S. R., Wintermantel, W. M., and Lewellen, R. T. 2002. Comparisons of soil and seed applied systemic insecticides to control beet curly top virus in the San Joaquin Valley. J. Sugar Beet Res. 39:59-74.

15. Klute, K. A., Nadler, S. A., and Stenger, D. C. 1996. Horseradish curly top virus is a distinct subgroup II geminivirus species with rep and $C 4$ genes derived from a subgroup III ancestor. J. Gen. Virol. 77:1369-1378.

16. Latham, J. R., Saunders, K., Pinner, M. S., and Stanley, J. 1997. Induction of plant cell division by beet curly top virus gene C4. Plant J. 11:12731283.

17. Soto, M. J., Chen, L.-F., Seo, Y.-S., and Gilbertson, R. L. 2005. Identification of regions of the Beet mild curly top virus (family Geminiviridae) capsid protein involved in systemic infection, virion formation and leafhopper transmission. Virology 341:257-270.

18. Stanley, J., Bisaro, D. M., Briddon, R. W., Brown, J. K., Fauquet, C. M., Harrison, B. D., Rybicki, E. P., and Stenger, D. C. 2005. Family Geminiviridae. Page 1259 in: Virus Taxonomy: Classification and Nomenclature of Viruses. The eighth report of the International Committee on taxonomy of viruses. Academic Press, Boston.

19. Stanley, J., Latham, J. R., Pinner, M. S., Bedford, I., and Markham, P. G. 1992. Mutational analysis of the monopartite geminivirus beet curly top virus. Virology 191:396-405.

20. Stanley, J., Markham, P. G., Callis, R. J., and Pinner, M. S. 1986. The nucleotide sequence of an infectious clone of the geminivirus beet curly top virus. EMBO J. 5:1761-1767.

21. Stenger, D. C. 1994. Complete nucleotide sequence of the hypervirulent CFH strain of beet curly top virus. Mol. Plant-Microbe Interact. 7:154157.

22. Stenger, D. C. 1998. Replication specificity elements of the Worland strain of beet curly top virus are compatible with those of the CFH strain but not those of the Cal/Logan strain. Phytopathology 88:1174-1178.

23. Stenger, D. C., Carbonaro, D., and Duffus, J. E. 1990. Genomic characterization of phenotypic variants of beet curly top virus. J. Gen. Virol. 71:2211-2215.

24. Stenger, D. C., Davis, K. R., and Bisaro, D. M. 1994. Recombinant beet curly top virus genomes exhibit both parental and novel pathogenic phenotypes. Virology 200:677-685.

25. Stenger, D. C., and McMahon, C. L. 1997. Genotypic diversity of beet curly top virus populations in the western United States. Phytopathology 87:737-744.

26. Stenger, D. C., and Ostrow, K. M. 1996. Genetic complexity of a beet curly top virus population used to assess sugar beet cultivar response to infection. Phytopathology 86:929-933.

27. Strausbaugh, C. A., Gillen, A. M., Camp, S., Shock, C. C., Eldredge, E. P., and Gallian, J. J. 2007. Relationship of beet curly top foliar ratings to sugar beet yield. Plant Dis. 91:1459-1463.

28. Strausbaugh, C. A., Gillen, A. M., Gallian, J. J., Camp, S., and Stander, J. R. 2006. Influence of host resistance and insecticide seed treatments on curly top in sugar beets. Plant Dis. 90:1539-1544.

29. Wintermantel, W. M., and Kaffka, S. R. 2006. Sugar beet performance with curly top is related to virus accumulation and age at infection. Plant Dis. 90:657-662. 